Quebec Cooperative Study

of Friedreich's Ataxia

\title{
Regional Distribution of Amino Acids in Friedreich's Ataxia Brains
}

\author{
R. HUXTABLE, J. AZARI. T. REISINE, P.JOHNSON, H. YAMAMURA, AND A. BARBEAU
}

SUMMARY: The distribution of amino acids in two Friedreich's ataxia brains is compared to 4 control brains. Glutamate and $G A B A$ n'ere decreased in the cerebellar hemispheres and/or in the vermis. Taurine concentrations were uniformly elevated throughout the areas studied. Taurine/glutamate and taurine/GABA ratios were consistently elevated in Friedreich's ataxia brains, whereas glutamate/ glutamine ratios w'ere consistently decreased (with normal glutamine concentrations).

RÉSUMÉ: Nous avons étudié la distribution des acides aminés dans le cerveau de deux cas d'ataxie de Friedreich et de 4 cerveaux témoins. La concentration du glutamate et du GABA est diminuée dans les hémisphères cérébelleux et/ou le vermis. La concentration en taurine est uniformément élevée dans les régions étudiées. Les rapports taurine/glutamate et taurine/GABA sont constamment élevés dans les cerveaux d'ataxie de Friedreich, alors que le rapport glutamate/glutamine est diminué en présence de concentrations normales de glutamine.
From the Departments of Pharmacology and Pathology, University of Arizona Health Sciences Center, Tucson, and the Clinical Research Institute of Montreal.

Reprint requests for the complete supplement on Friedreich's Ataxia (Phase Two, Part Two) to:

Dr. André Barbeau, M.D., Clinical Research Institute of Montreal, 110 Pine Avenue West, Montreal, Quebec, Canada, H2W IR7.

\section{INTRODUCTION}

There are no reports of the concentrations of free amino acids in the brains of Friedreich's ataxia patients. The possibility that alterations in amino acid concentrations are related to the pathogenesis of the disease has assumed greater importance as a result of the findings of Lemieux et al. (1976) on the disturbances of amino acide is plasma and urine. Among the many disturbances found by these authors, was an apparent defect in the tubular resorption of taurine in the kidney. The taurine content of urine was doubled in Friedreich's ataxia patients compared to control subjects.

Disturbances in taurine regulation are of potential significance in that Friedreich's ataxia is a spinocerebellar degeneration, and there is strong evidence implicating taurine as a neurotransmitter in the cerebellum (McBride and Frederickson, 1978). The possible involvement of taurine in the cardiomyopathy of Friedreich's ataxia has been discussed by Huxtable (1978).

In this paper, we report the result of amino acid analyses of the brains of two Friedreich's ataxia patients, and four control brains from subjects dying of non-neurological disorders.

\section{METHODS}

The subjects are described in an accompanying paper (Reisine et al., 1979). The regions of the brain examined were; dentate nucleus, anterior cerebellar vermis, posterior cerebellar vermis, cerebellar hemisphere, inferior olive nucleus, red nucleus and dorsal root ganglion. In addition, on one of the Friedreich's ataxia patients, we obtained analyses of the lumbar spinal cord and the thoracic spinal cord.

Amino Acid Analyses:

Brain tissues were thawed and homogenized $10: 1$ in $3.5 \%$ sulfosalicylic acid. Homogenates were centrifuged and the supernatants added to a half volume of $0.3 \mathrm{~N}$ lithium hydroxide. Aliquots of this solution were analyzed on a Beckham Model 118 amino acid analyzer. $\alpha$-Amino-nbutyric acid was used as internal standard.

Statistical analyses were performed by the Student unpaired ' $t$ ' test. Data are reported as means \pm one standard deviation.

\section{RESULTS}

Analytical results are shown in Table 1. Numerous differences can be observed, although the small number of samples militates against statistical significance. For areas in which six brains were analyzed, six statistically significant differences occur. Glutamate concentration is significantly lowered in the cerebellar hemisphere and the posterior cerebellar vermis. GABA concentrations are significantly decreased in the same two areas, and also in the anterior cerebellar vermis. Aspartate, glutamate, phenylalanine, and GABA are uniformly decreased in concentration in all brain areas examined. Taurine is the only amino acid to be increased in all the brain areas examined. Figure 1 illustrates the individual values of the neurotransmitter amino acids in the various brain areas. In the Friedreich's ataxia samples, taurine shows a marked regional variability, ranging from 0.6 $\mu$ mole / $\mathrm{g}$ in the dorsal root ganglion to $3.8 \mu \mathrm{mole} / \mathrm{g}$ in the cerebellar hemisphere. However, a different 
TABLE 1

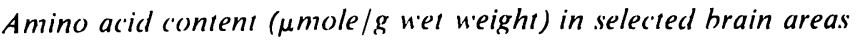

\begin{tabular}{|c|c|c|c|c|c|c|c|c|c|}
\hline Control & $\begin{array}{l}\text { CH } \\
\text { (4) }\end{array}$ & \multicolumn{2}{|l|}{$\begin{array}{c}\text { PCV } \\
\text { (4) }\end{array}$} & $\begin{array}{c}\mathrm{ACV} \\
\mathbf{( 4 )}\end{array}$ & $\underset{(3)}{10 N}$ & $\begin{array}{l}\text { DN } \\
\text { (3) }\end{array}$ & \multicolumn{2}{|r|}{$\begin{array}{l}\text { RN } \\
\text { (1) }\end{array}$} & $\begin{array}{c}\text { DRG } \\
\text { (1) }\end{array}$ \\
\hline Tau & $2.21 \pm 1.03$ & \multicolumn{2}{|l|}{$1.96 \pm 0.92$} & $1.61 \pm 0.73$ & $0.95 \pm 0.49$ & $1.35 \pm 0.71$ & \multicolumn{2}{|r|}{1.58} & 0.47 \\
\hline Thr & $0.94 \pm 0.32$ & \multicolumn{2}{|l|}{$0.97 \pm 0.25$} & $0.82 \pm 0.20$ & $0.62 \pm 0.33$ & $0.78 \pm 0.15$ & \multicolumn{2}{|r|}{0.35} & 0.31 \\
\hline Asp & $1.57 \pm 1.01$ & \multicolumn{2}{|l|}{$1.75 \pm 1.14$} & $1.44 \pm 1.03$ & $0.66 \pm 0.41$ & $1.22 \pm 0.22$ & \multicolumn{2}{|r|}{1.53} & 0.38 \\
\hline Ser & $1.16 \pm 0.77$ & \multicolumn{2}{|l|}{$1.24 \pm 0.56$} & $1.00 \pm 0.48$ & $0.75 \pm 0.18$ & $1.10 \pm 0.50$ & \multicolumn{2}{|r|}{0.75} & 0.38 \\
\hline Gln & $5.38 \pm 1.62$ & \multicolumn{2}{|l|}{$6.36 \pm 3.38$} & $3.59 \pm 1.89$ & $5.33 \pm 4.52$ & $6.19 \pm 3.83$ & \multicolumn{2}{|r|}{8.62} & 0.21 \\
\hline Glu & $10.14 \pm 2.63$ & \multicolumn{2}{|l|}{$12.51 \pm 3.36$} & $7.71 \pm 3.93$ & $4.98 \pm 3.30$ & $6.75 \pm 2.70$ & \multicolumn{2}{|r|}{7.49} & 1.09 \\
\hline Gly & $1.96 \pm 0.93$ & \multicolumn{2}{|l|}{$2.20 \pm 0.86$} & $1.71 \pm 0.82$ & $1.68 \pm 0.87$ & $1.85 \pm 0.56$ & \multicolumn{2}{|r|}{1.58} & 0.54 \\
\hline Ala & $2.11 \pm 0.61$ & \multicolumn{2}{|l|}{$2.39 \pm 0.56$} & $1.95 \pm 0.59$ & $1.83 \pm 0.84$ & $1.76 \pm 0.31$ & \multicolumn{2}{|r|}{1.89} & 0.90 \\
\hline Val & $0.75 \pm 0.38$ & $0.77 \pm 0.26$ & 0.58 & .30 & $0.54 \pm 0.16$ & $0.66 \pm 0.29$ & & trace & 0.37 \\
\hline Cysta & $0.45 \pm 0.12$ & $0.49 \pm 0.11$ & 0.37 & .05 & $0.96 \pm 0.78$ & $1.52 \pm 0.79$ & & 1.46 & 0.00 \\
\hline Met & $0.39 \pm 0.18$ & $0.41 \pm 0.10$ & 0.36 & .13 & $0.36 \pm 0.04$ & $0.33 \pm 0.09$ & & 0.52 & 0.13 \\
\hline Isoleu & $0.47 \pm 0.23$ & $0.47 \pm 0.14$ & 0.41 & .14 & $0.38 \pm 0.02$ & $0.42 \pm 0.13$ & & 0.35 & 0.22 \\
\hline Leu & $1.00 \pm 0.43$ & $1.05 \pm 0.30$ & 0.92 & .28 & $0.69 \pm 0.13$ & $0.81 \pm 0.23$ & & 0.74 & 0.31 \\
\hline Tyr & $0.49 \pm 0.13$ & $0.52 \pm 0.09$ & 0.45 & .14 & $0.43 \pm 0.21$ & $0.46 \pm 0.09$ & & 0.21 & 0.20 \\
\hline Phe & $0.59 \pm 0.15$ & $0.62 \pm 0.08$ & 0.53 & .11 & $0.49 \pm 0.18$ & $0.52 \pm 0.03$ & & 0.26 & 0.21 \\
\hline GABA & $1.41 \pm 0.45$ & $1.99 \pm 0.52$ & 1.55 & .20 & $1.02 \pm 0.32$ & $3.18 \pm 1.15$ & & 1.75 & - \\
\hline $\begin{array}{l}\text { Friedreich's } \\
\text { ataxia }\end{array}$ & $\begin{array}{l}\text { CH } \\
\text { (2) }\end{array}$ & $\begin{array}{c}\text { PCV } \\
\text { (2) }\end{array}$ & $\begin{array}{c}\text { ACV } \\
\text { (2) }\end{array}$ & $\begin{array}{c}\text { ION } \\
\text { (1) }\end{array}$ & $\begin{array}{l}\text { DN } \\
\text { (2) }\end{array}$ & $\begin{array}{l}\text { RN } \\
\text { (2) }\end{array}$ & $\begin{array}{c}\text { DRG } \\
\text { (1) }\end{array}$ & $\begin{array}{c}\text { LSC } \\
\text { (1) }\end{array}$ & $\begin{array}{c}\text { TSC } \\
\text { (1) }\end{array}$ \\
\hline Tau & $3.78 \pm 0.61$ & $2.38 \pm 0.84$ & $2.56 \pm 0.07$ & 3.05 & $3.49 \pm 3.26$ & $1.13 \pm 0.06$ & 0.63 & 0.96 & 1.37 \\
\hline Thr & $0.48 \pm 0.01$ & $0.51 \pm 0.08$ & $0.59 \pm 0.03$ & 1.13 & $0.86 \pm 0.94$ & $1.33 \pm 1.43$ & 0.43 & 0.42 & 0.49 \\
\hline Asp & $0.75 \pm 0.36$ & $0.92 \pm 0.08$ & $1.00 \pm 0.13$ & 1.20 & $0.93 \pm 0.11$ & $0.90 \pm 0.21$ & 0.31 & 0.90 & 1.29 \\
\hline Ser & $0.64 \pm 0.14$ & $0.71 \pm 0.23$ & $0.83 \pm 0.21$ & 2.30 & $1.47 \pm 1.56$ & $0.89 \pm 0.45$ & 0.36 & 0.51 & 0.60 \\
\hline Gln & $4.98 \pm 2.22$ & $5.13 \pm 1.35$ & $5.60 \pm 2.80$ & 4.08 & $9.27 \pm 5.71$ & $5.36 \pm 3.54$ & 1.27 & 0.45 & 4.95 \\
\hline Glu & $4.42 \pm 0.83^{\mathrm{a}}$ & $4.55 \pm 0.73^{\mathrm{a}}$ & $4.12 \pm 0.88$ & 4.02 & $4.12 \pm 1.90$ & $4.98 \pm 0.39$ & 0.97 & 2.84 & 7.05 \\
\hline Gly & $1.17 \pm 0.33$ & $1.28 \pm 0.34$ & $1.33 \pm 0.37$ & 3.35 & $2.33 \pm 1.99$ & $1.98 \pm 1.14$ & 0.88 & 2.06 & 1.48 \\
\hline Ala & $1.25 \pm 0.30$ & $1.26 \pm 0.42$ & $1.43 \pm 0.22$ & 2.96 & $2.52 \pm 1.73$ & $1.78 \pm 0.39$ & 1.33 & 1.39 & 1.36 \\
\hline Val & $0.38 \pm 0.13$ & $0.58 \pm 0.43$ & $0.60 \pm 0.06$ & 1.54 & $1.04 \pm 1.29$ & $0.48 \pm 0.01$ & 0.37 & 1.06 & 0.36 \\
\hline Cysta & $0.23 \pm 0.18$ & $0.58 \pm 0.54$ & $0.21 \pm 0.15$ & 0.27 & $0.51 \pm 0.40$ & $0.66 \pm 0.49$ & 0.05 & 0.19 & 0.49 \\
\hline Met & $0.24 \pm 0.01$ & $0.29 \pm 0.10$ & $0.38 \pm 0.01$ & 1.03 & $0.61 \pm 0.66$ & $0.43 \pm 0.16$ & 0.19 & 0.28 & 0.26 \\
\hline Isoleu & $0.21 \pm 0.06$ & $0.31 \pm 0.11$ & $0.15 \pm 0.00$ & 0.72 & $0.47 \pm 0.47$ & $0.43 \pm 0.13$ & 0.26 & 0.13 & 0.22 \\
\hline Leu & $0.43 \pm 0.12$ & $0.59 \pm 0.16$ & $0.49 \pm 0.19$ & 1.63 & $1.09 \pm 1.10$ & $0.78 \pm 0.28$ & 0.41 & 0.36 & 0.39 \\
\hline Tyr & $0.37 \pm 0.00$ & $0.35 \pm 0.10$ & $0.45 \pm 0.01$ & 0.84 & $0.58 \pm 0.47$ & $0.46 \pm 0.01$ & 0.36 & 0.21 & 0.33 \\
\hline Phe & $0.32 \pm 0.04$ & $0.32 \pm 0.08^{c}$ & $0.42 \pm 0.03$ & 0.64 & $0.48 \pm 0.39$ & $0.48 \pm 0.01$ & 0.33 & 0.16 & 0.28 \\
\hline GABA & $0.73 \pm 0.08^{\mathrm{a}}$ & $0.95 \pm 0.17^{\mathrm{a}}$ & $0.97 \pm 0.11^{\mathrm{b}}$ & 0.83 & $1.52 \pm 1.10$ & $2.13 \pm 0.78$ & 0.07 & 0.55 & 0.37 \\
\hline
\end{tabular}

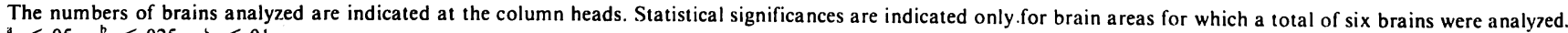
a $p<.05$, ${ }^{\mathrm{p}} \mathrm{p}<.025$, ' $\mathrm{p}<.01$

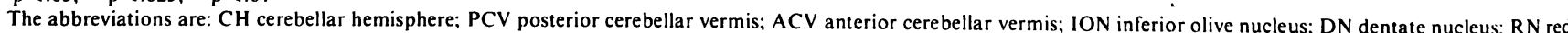
nucleus; DRG dorsal root ganglion; LSC lumbar spinal cord; TSC thoracic spinal cord.

picture is seen with glutamic acid (Fig. 1b). Control brains show marked regional variations in concentration and the standard deviation about the mean in a given brain area is high. In the Friedreich's ataxia brains, however, glutamic acid concentrations are invariant in all the areas examined. Furthermore, little difference is seen between the two brains. Qualitatively, the same phenomenon occurs with the other neurotransmitter amino acids GABA (Fig. 1c) and aspartic acid (Fig. 1d).
The ratios of concentrations of neurotransmitter amino acids may be of greater relevance than the absolute concentrations (Van Gelder 1978). Selected ratios are illustrated in Table 2 . In the four brain areas reported, taurinexglutamate and taurine/ GABA ratios are consistently elevated in Friedreich's ataxia brains, whereas glutamate/glutamine ratios are consistently decreased. No alteration occurs in GABA/glutamate ratio. The changes in glutamate/glutamine ratios are due to altered glutamate concentration, glutamine levels being normal in Friedreich's ataxia brains.

\section{DISCUSSION}

Although our data are based on only two Friedreich's ataxia brains and four control brains, they are of interest in that brain amino acid levels have rarely been reported for any ataxia, and are unreported for Friedreich's ataxia.

Despite the small number of brains reported on here, a number of differences are clearly established. In 

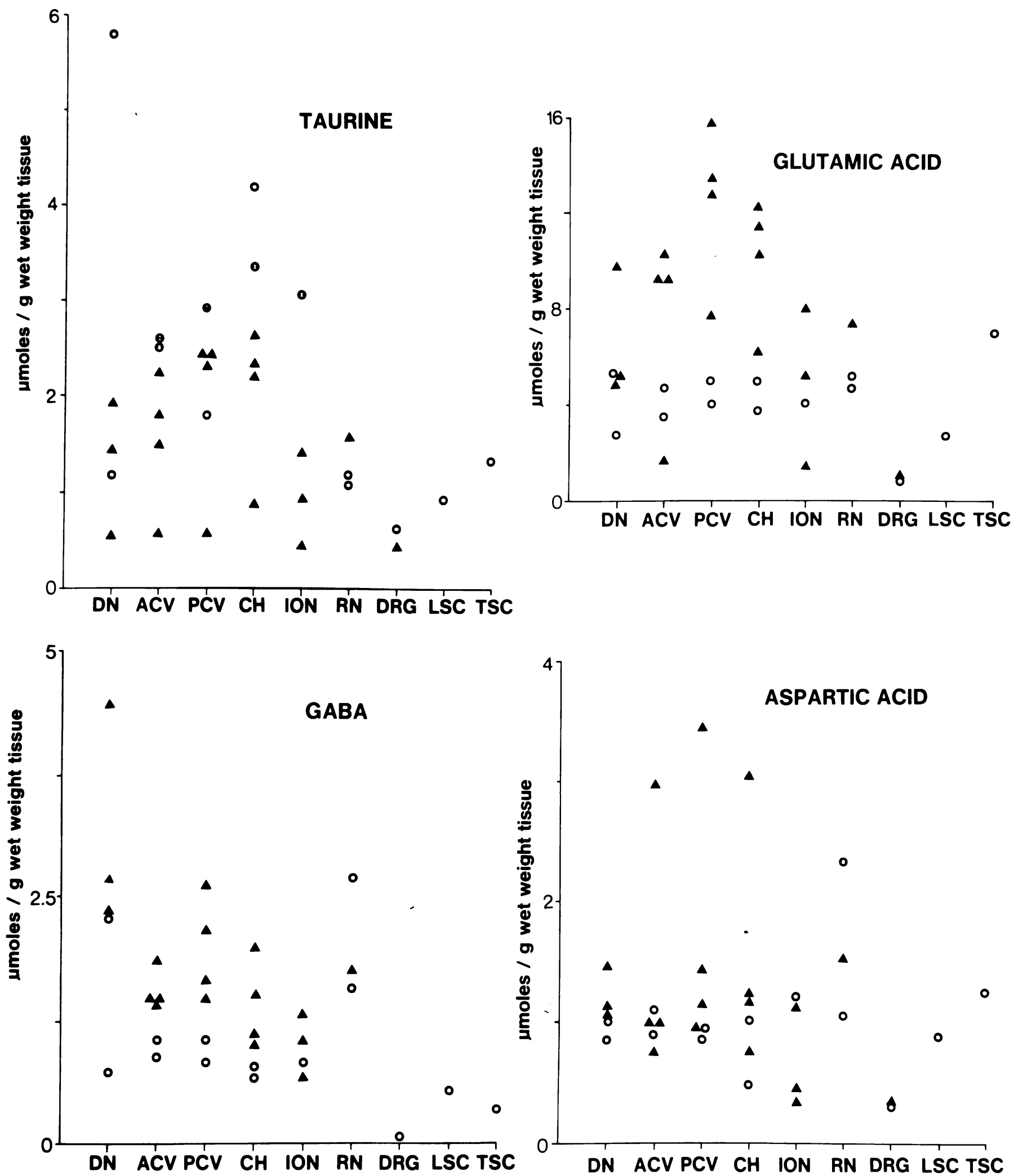

Figure I-Neurotransmitter amino acid concentrations. Abbreviations for brain areas are given in Table 1. $\Delta$ : control brains 0 : Friedreich's ataxia brains 
TABLE 2

Selected Amino Acid Ratios

\begin{tabular}{|c|c|c|c|c|}
\hline Control & $\begin{array}{l}\text { CH } \\
\text { (4) }\end{array}$ & $\begin{array}{c}\text { PCV } \\
\text { (4) }\end{array}$ & $\begin{array}{c}\text { ACV } \\
\text { (4) }\end{array}$ & $\begin{array}{l}\text { DN } \\
\text { (3) }\end{array}$ \\
\hline Tau/glu & $0.24 \pm 0.14$ & $0.18 \pm 0.11$ & $0.37 \pm 0.42$ & $0.23 \pm 0.15$ \\
\hline $\mathrm{Tau} / \mathrm{GABA}$ & $1.57 \pm 0.63$ & $1.00 \pm 0.52$ & $1.05 \pm 0.50$ & $0.51 \pm 0.36$ \\
\hline GABA/glu & $0.14 \pm 0.04$ & $0.16 \pm 0.04$ & $0.32 \pm 0.30$ & $0.47 \pm 0.04$ \\
\hline $\mathrm{Glu} / \mathrm{gln}$ & $1.94 \pm 0.55$ & $2.32 \pm 1.23$ & $2.20 \pm 1.05$ & $1.22 \pm 0.38$ \\
\hline $\begin{array}{l}\text { Friedreich's } \\
\text { ataxia }\end{array}$ & (2) & (2) & (2) & (2) \\
\hline Tau/glu & $0.89 \pm 0.30^{\circ}$ & $0.55 \pm 0.28$ & $0.64 \pm 0.12$ & $0.74 \pm 0.45$ \\
\hline Tau/GABA & $5.17 \pm 0.23^{c}$ & $2.62 \pm 1.38$ & $2.66 \pm 0.23^{h}$ & $4.17 \pm 5.17$ \\
\hline GABA/glu & $0.17 \pm 0.06$ & $0.21 \pm 0.00$ & $0.24 \pm 0.02$ & $0.49 \pm 0.49$ \\
\hline Glu/gln & $0.94 \pm 0.25$ & $0.90 \pm 0.10$ & $0.80 \pm 0.24$ & $0.63 \pm 0.59$ \\
\hline
\end{tabular}

$" \mathrm{p}<.025 ; \quad{ }^{n} \mathrm{p}<.01 ; \quad \mathrm{p}<<.001$

general, changes in amino acid content are limited to neurotransmitter substances. Glutamic acid, glutamine, and GABA are metabolically closely linked. Glutamic acid, an excitatory amino acid, is converted to GABA, an inhibitory amino acid, by the enzyme glutamic acid decarboxylase. Both of these amino acids are significantly decreased in concentration in the cerebellar hemisphere and the posterior cerebellar vermis. Additionally, GABA concentration is significantly decreased in the anterior cerebellar vermis. Glutamine concentration, on the other hand, is normal in all the areas examined. Glutamine is present largely in glia (MartinezHernandez et al., 1977), whereas glutamate is present largely in neuronal elements (Berl et al., 1970). One significant normal function of glutamine is to buffer the glutamate concentration by means of a ready 1978). It seems that in Friedreich's ataxia brains this buffering capacity has been lost. The most remarkable observation made in this study is the uniform concentration of glutamic acid found in the different areas of the Friedreich's ataxia brains. The significance of this must await further work. transamination reaction (Van Gelder,

\section{ACKNOWLEDGMENTS}

These studies were supported by L'Association Canadienne de l'Ataxie de Friedreich, and by NIH Grant HL-19394.

\section{REFERENCES}

BERL, S., CLARKE, D.D., and NICKLAS W.J. (1970). Compartmentation of citric acid metabolism in brain: effect of aminooxyacetic acid, oubain and $\mathrm{Ca}^{2}$ on the labelling of glutamate, glutamine, aspartate and $\mathrm{GABA}$ by $\left[1-{ }^{14} \mathrm{C}\right]$ acetate, $\left[\mathrm{U}-{ }^{14} \mathrm{C}\right]$ glutamate and $\left[\mathrm{U}-14^{-14}\right.$ aspartate. $J$. Neurochem. 17, 999-1007.

HUXTABLE, R. J. (1978). Cardiac pharmacology and cardiomyopathy in Friedreich's ataxia. Can. J. Neurol. Sci. 5, 83-92.

LEMIEUX, B., BARBEAU, A., BERONIADE, V., SHAPCOTT, D., BRETON, G., GEOFFROY, G. and MELANCON, S. (1976). Amino acid metabolism in Friedreich's ataxia. Can. J. Neurol. Sci. 4, 373378.

MARTINEZ-HERNANDEZ, A., BELL, K.P., and Norenberg, M.D. (1977). Glutamine synthetase: glial localization in brain. Science 195, 1356-1358.

McBRIDE, W.J. and FREDERICKSON, R.C.A. (1978). Neurochemical and neurophysiological evidence for a role of taurine as an inhibitory neurotransmitter in the cerebellum of the rat, in "Taurine and Neurological Disorders," Eds., Barbeau, A. and Huxtable, R. pp 415-427. Raven Press, New York.

REISINE, T., AZARI, J., JOHNSON, P.C. BARBEAU, A., HUXTABLE, R. and YAMAMURA, H.I. (1978). Brain neurotransmitter receptors in Friedreich's ataxia. Can. J. Neurol. Sci. (this issue).

VAN GELDER, N.M. (1978). Taurine, the compartmentalized metabolism of glutamic acid, and the epilepsies. Can. J. Physiol. Pharmacol. 56, 362-374. 